Marquette University
e-Publications@Marquette

Civil and Environmental Engineering Faculty Research and Publications
Civil, Construction, and Environmental Engineering, Department of

8-2016

\title{
Framework for Incorporating Probabilistic Building Performance in the Assessment of Community Seismic Resilience
}

\author{
Henry V. Burton \\ University of California, Los Angeles \\ Gregory Deierlein \\ Stanford University \\ David Lallemant \\ Stanford University \\ Ting Lin \\ Marquette University, ting.lin@marquette.edu
}

Follow this and additional works at: https://epublications.marquette.edu/civengin_fac

Part of the Civil Engineering Commons

\section{Recommended Citation}

Burton, Henry V.; Deierlein, Gregory; Lallemant, David; and Lin, Ting, "Framework for Incorporating

Probabilistic Building Performance in the Assessment of Community Seismic Resilience" (2016). Civil and Environmental Engineering Faculty Research and Publications. 162.

https://epublications.marquette.edu/civengin_fac/162 
Marquette University

e-Publications@Marquette

\section{Civil and Environmental Engineering Faculty Research and Publications/College of Engineering}

This paper is NOT THE PUBLISHED VERSION; but the author's final, peer-reviewed manuscript. The published version may be accessed by following the link in th citation below.

Journal of Structural Engineering, Vol. 142, No. 8 (August 2016): C4015007-1/11. DOI. This article is (C) American Society of Civil Engineers and permission has been granted for this version to appear in ePublications@Marquette. American Society of Civil Engineers does not grant permission for this article to be further copied/distributed or hosted elsewhere without the express permission from American Society of Civil Engineers.

\section{Framework for Incorporating Probabilistic Building Performance in the Assessment of Community Seismic Resilience}

Henry V. Burton

Department of Civil and Environmental Engineering, University of California, Los Angeles, CA Gregory Delerlein

Department of Civil and Environmental Engineering, Stanford University, Stanford, CA David Lallemant

Department of Civil and Environmental Engineering, Stanford University, Stanford, CA Ting Lin

Department of Civil and Environmental Engineering, Marquette University, Milwaukee, WI 


\section{Abstract}

A framework is presented for incorporating probabilistic building performance limit states in the assessment of community resilience to earthquakes. The limit states are defined on the basis of their implications to postearthquake functionality and recovery. They include damage triggering inspection, occupiable damage with loss of functionality, unoccupiable damage, irreparable damage, and collapse. Fragility curves are developed linking earthquake ground motion intensity to the probability of exceedance for each of the limit states. A characteristic recovery path is defined for each limit state on the basis of discrete functioning states, the time spent within each state, and the level of functionality associated with each state. A building recovery function is computed accounting for the uncertainty in the occurrence of each recovery path and its associated limit state. The outcome is a probabilistic assessment of recovery of functionality at the building level for a given ground motion intensity. The effects of externalities and other socioeconomic factors on building-level recovery and ways to incorporate these in the framework are discussed. A case study is presented to demonstrate the application of the proposed framework to model the postearthquake recovery of the shelter-in-place housing capacity of an inventory of residential buildings. This type of assessment can inform planning and policy decisions to manage the earthquake risk to residential housing capacity of communities.

\section{Introduction}

The performance-based earthquake engineering (PBEE) framework developed by the Pacific Earthquake Engineering Research (PEER) Center and implemented in FEMA P58 (Cornell and Krawinkler 2000; Moehle and Deierlein 2004; Krawinkler and Miranda 2004; FEMA 2012) has become the cornerstone approach for assessing the seismic performance of individual buildings and facilities. It provides a rigorous methodology for performing probabilistic seismic hazard analysis, evaluating relevant engineering demand parameters and quantifying damage measures and associated repair/replacement costs. Although the PBEE framework represents a major step forward toward quantifying and managing earthquake risks of individual buildings, a much broader interpretation of performance is needed to understand how communities will be affected and recover from devastating earthquakes (Krawinkler and Deierlein 2013). More recently, earthquake engineering researchers and practitioners have embraced the concept of seismic resilience as a measure of a community's ability to contain the effects of an earthquake and achieve a timely recovery.

The Multidisciplinary Center for Earthquake Engineering Research developed a conceptual framework for quantifying seismic resilience (Bruneau et al. 2003), which outlines four properties of resilience (robustness, redundancy, resourcefulness, and rapidity) and four dimensions of resilience (technical, organizational, social, and economic). Resilience is quantified by using a multidimensional space of performance measures that includes the probability of failure, the consequences of failure, and time to recovery. This work was extended by Cimellaro et al. (2010b) to include an analytical methodology for quantifying disaster resilience that provides a unified terminology and common reference framework, 
which was applied to evaluate the seismic resilience of health care facilities. In a report on the L'Aquila earthquake of 2009, Cimellaro et al. (2010a) further extend these ideas to a resilience-based design (RBD) framework, in which the aim is to inform the design of individual structures on the basis of community resilience considerations. Cimellaro et al. (2011) also developed a performance-based metamodel for health care facilities to relate the earthquake response and damage of structural and nonstructural components of hospitals to overall functional effectiveness of the health care organization.

Miles and Chang $(2003,2006,2007,2011)$ and Miles (2014) developed a conceptual model of community recovery (ResilUS) that they extended to a numerical model. Their conceptual model "was built up by characterizing the attributes and behaviors of economic agents within a community, such as households and businesses, and describing relationships between agents themselves and relationships with their environment, such as buildings of residence and transportation networks." The functions used to represent recovery trajectories are implemented as Markov chains, capturing the time spent in various states of damage, defined according to some fraction of the building value. The model was operationalized into a computer simulation platform (ResilUS) and used to conduct case studies for the Northridge and Kobe earthquakes.

Twigg (2009) identified 28 components of resilience that are organized into five thematic areas: governance, risk assessment, knowledge and education, risk management and vulnerability reduction, and preparedness and response. A similar approach was developed by Cutter et al. (2010), in which a set of 36 baseline indicators were used to measure and monitor the resilience of communities to disasters. The resilience of a particular community is based on an aggregated resilience index, which incorporates five main categories including social resilience, economic resilience, institutional resilience, infrastructure resilience, and community capital.

Mieler et al. (2014) developed a framework for linking community resilience goals to specific performance targets for the built environment. The framework is based on a design and evaluation philosophy that involves (1) specifying a performance objective at the community level, (2) identifying an undesirable outcome and acceptable level of risk associated with the occurrence of this outcome, (3) identifying vital community functions that must be maintained to prevent the undesirable outcome, and (4) using probabilistic risk assessment to establish a relationship between the probability of losing these vital functions and the occurrence of the undesirable outcome.

The San Francisco Planning and Urban Research Association (SPUR) outlined a comprehensive set of performance objectives for its buildings and lifeline infrastructure 
that are needed to make San Francisco more resilient to earthquakes (Poland et al. 2009). Seismic performance targets for facilities and systems are defined based on their implication to postearthquake functionality and recovery. Building damage is characterized by the following performance categories: (1) safe and operational, (2) safe and usable during repair, (3) safe but not repairable, and (4) unsafe. By using these categories, specific target goals for building and infrastructure are established, considering citywide needs. In addition to establishing these target goals, estimates of the performance of the current inventory were assessed, albeit based largely on "educated guesses about current standards for recovery time." The immediate postearthquake limit state of a community's building infrastructure is identified as having a significant impact on its ability to recover in a timely manner. For example, the SPUR report notes that the ability of a region to provide safe housing immediately after an earthquake influences the likelihood that there will be a significant outmigration of its residents.

Most of the previous approaches to modeling postearthquake recovery have relied on the generic damage states used in loss estimation (e.g., none, slight, and moderate), which are not related to recovery. A rigorous evaluation of seismic resilience requires methods for incorporating the probabilistic assessment of multiple limit states, which are explicitly linked to recovery of the building inventory. The PEER PBEE methodology provides an approach for quantifying building damage measures that inform repair and replacement activities. This study demonstrates how the current PBEE framework can be adapted and incorporated into a resilience framework to model recovery at the individual building and community scales. It incorporates the assessment of a set of building performance limit states that specifically inform community seismic resilience. These limit states have been adapted from the building performance categories defined by SPUR. A building-level recovery model is proposed, which is probabilistically linked to the limit states. The framework is implemented to assess the immediate postearthquake reduction and recovery trajectory of the shelter-in-place housing capacity of a residential community. Guidance is provided for considering the effect of externalities and other socioeconomic factors on recovery.

\section{Overview of Framework}

An overview of the proposed framework is illustrated in Fig. 1. The PEER PBEE framework is applied to each building within the target community, incorporating new damage measures and a new decision variable, the outcome of which is a recovery function that is generated for individual buildings. In the next stage, the building-level metrics are aggregated to produce measures of community-level performance. 
Hazard analysis requires quantification of the joint occurrence of ground motion intensities at the sites of the individual buildings in the study region for one or more scenario earthquakes. This scenario-based quantification of seismic hazard is commonly used in risk assessment of spatially distributed building portfolios or infrastructure systems.

Computational tools such as HAZUS (FEMA 1999) and OpenQuake (Silva et al. 2012) are able to simulate scenario earthquakes using geostatistical models.

Structural response analyses are performed to obtain the engineering demand parameters (e.g., story drift, residual story drift, and floor acceleration), which inform the damage assessment conducted in the next step. Nonlinear dynamic analysis is used for simulating the response of building structures from the initiation of damage up to the onset of collapse. Archetype models can be used to assess the seismic performance of a portfolio of buildings within a region. A single archetype is used to represent multiple buildings with similar structural performance characteristics, thereby reducing the number of models that need to be constructed and analyzed. In the event that the numerical modeling of the entire building portfolio becomes unfeasible as a result of limited building data or computational expense, the building damage fragility curves can be developed by using empirical or heuristic methods.

The engineering demand parameters from structural analyses are used to generate building fragility curves that link ground motion intensity to the probability of exceeding each of five limit states described subsequently in this paper. The outcome of this stage is different from that of the current PBEE framework, which relates demand parameters to building component damage, which are then translated into repair costs and times. The building limit states include (1) damage triggering inspection, (2) occupiable damage with loss of functionality, (3) unoccupiable damage, (4) irreparable damage, and (5) collapse.

A new decision variable is derived from the limit states, describing the recovery of functionality at the building level. In the final stage of the framework, normalized building recovery functions are aggregated to quantify community-level performance.

The first two steps of the proposed framework (hazard analysis and structural analysis) closely follow the current PBEE methodology and are fairly well-established. This study focuses on the damage and decision metrics that are an extension of the current PBEE framework. Guidelines are also provided for using the results of the building-level assessment to quantify the reduction and recovery of the housing capacity of a residential community. This includes approaches to incorporating the effect of externalities and socioeconomic factors on recovery. 
Building Performance Limit States Used in Resilience Assessment

Five discrete limit states $(L S)$ are used, which are explicitly linked to postearthquake recovery-related activities. Each limit state is associated with a unique combination of the following consequent actions to restore building function:

- Assessment and planning activities, i.e., postearthquake inspection and/or evaluation, preparation of plans and designs, financing and bidding preparation for construction work;

- For repairable buildings: (1) repairs needed to make building occupiable, and (2) repairs needed to restore functionality; and

- For nonrepairable buildings: demolition and building replacement.

$L S_{1}$ : Damage Triggering Inspection with Functionality Maintained

$L S_{1}$ represents the minimum damage threshold that would require postearthquake inspection and/or evaluation. It is also used to imply a level of damage in which, despite the need for postearthquake inspection, the structural safety and critical subsystems essential to the functionality of the building are not compromised. However, operations may be affected if the owner/operator decides to close the facility until inspections are completed. This decision is prompted by visible damage to structural (cracking of concrete members) or nonstructural elements (e.g., partitions and facades). This type of damage occurs at low drift levels and affects structural and nonstructural components with low deformation capacities. The approach used to assess this limit state is very similar to the FEMA P58 (FEMA 2012) methodology for determining whether a building is unoccupiable after an earthquake, the difference being that the extent of damage associated with the limit state is based on the potential to prompt evacuation and postearthquake inspections. Obviously, the level of damage that would render a building unsafe to occupy will be more significant than that which triggers inspection. This assessment can be performed at multiple ground motion intensities, using structural response data from dynamic analysis to produce fragility curves that link ground motion intensity to the probability of exceeding the limit state.

$L S_{2}$ : Occupiable Damage with Loss of Functionality

$L S_{2}$ implies that the building is structurally safe, occupiable, and accessible but unable to carry out its primary function. This loss of functionality can occur despite the preservation of structural integrity as a result of damage to building systems, nonstructural components, 
or contents, which are critical to the operations of the facility. There may also be damage to structural components whose repair actions hinder normal building operations.

A system reliability approach is used to assess the probability of exceeding $L S_{2}$, whereby the building is viewed as a system that consists of several subsystems essential to day-today operations. An example of a function block diagram, considering some of the systems essential for functionality of a residential building, is shown in Fig. 2 . The subsystems are configured in series or parallel and connected by lines that do not necessarily represent physical linkages. A system consisting of components in series will fail if any one of the subcomponents fail, whereas a system with components in parallel will only fail if all of the parallel subcomponents fail. Most systems can be idealized as a combination of these two configurations. The subsystems shown in Fig. 2, electric power, water, and stair/elevator access, are examples of the services that may be considered essential for residential buildings. The designation of "essential" can depend on the functioning state, socioeconomic values, and cultural norms of the community stakeholders. For example, whether or not a building can be occupied for shelter-in-place may depend on the size of the building (e.g., a single family house versus a high-rise condominium building), the criticality of systems to occupancy (e.g., whether temporary alternatives are available to meet occupant needs), or the duration of interruption (e.g., willingness to endure inconveniences for a limited time). A residential building is one of the simpler systems to model in terms of the number and complexity of its essential subsystems. Other building types such as hospitals, data centers, and manufacturing facilities are likely to have a much larger number of subsystems with complex interactions and dependencies. The subsystems shown in Fig. 2 may either be affected by damage to the facility itself or to external services whose disruption could impact functionality. The relevance of these externalities will be discussed subsequently in this paper.

The probability of exceedance can be computed from the probability of failure of the various subsystems. By referring again to the subsystems shown in Fig. 2, the probability of exceeding limit state $L S_{2}$ would be described by using the following equation:

$$
P\left(L S \geq \mathrm{ls}_{2} \mid \mathrm{IM}\right)=P\left[\left(F_{\mathrm{EL}} \cap F_{\mathrm{ST}}\right) \cup F_{\mathrm{WS}} \cup F_{\mathrm{ES}}\right]
$$

where $P\left(L S \geq \mathrm{ls}_{2} \mid \mathrm{IM}\right)=$ probability of meeting or exceeding $L S_{2}$ at a given ground motion IM level; $F_{\mathrm{EL}}=$ loss of elevator access; $F_{\mathrm{ST}}=$ loss of stair access; $F_{\mathrm{WS}}=$ failure of the water supply; and $F_{\mathrm{ES}}$ = failure of the electrical supply. The right side of the equation can be solved by using established probability theory given the probability of failure for 
each component, which is determined from fragility relationships that link ground motion intensity to the probability of component failure.

\section{$L S_{3}$ : Unoccupiable Damage}

$L S_{3}$ infers that the building is either inaccessible or not safe to occupy after an earthquake. The loss of structural safety will likely be caused by a substantial loss in the load carrying capacity of the gravity or lateral system that poses a life safety threat in the event of an aftershock. It is also possible but less likely for nonstructural damage to compromise the safety of or prevent access to the building. This is usually in the form of some type of falling hazard (e.g. brick façade or infill panels); however, these types of dangers can be mitigated in a short period. $L S_{3}$ is of particular importance to residential buildings, as it is directly related to the shelter-in-place performance goal emphasized in SPUR's resilient city initiative. Similar to $L S_{1}, L S_{3}$ can be assessed by using the FEMA P58-1 (FEMA 2012) methodology. A building may also be rendered inaccessible as a result of external conditions (e.g., damaged roads and bridges, and collapse risk of neighboring buildings), which are discussed subsequently.

\section{$L S_{4}$ : Irreparable Damage}

$L S_{4}$ pertains to cases in which the building is damaged to such an extent that repair becomes technically or cost-prohibitive, necessitating demolition and replacement. The three main earthquake-related situations that can lead to demolition include (1) large permanent deformations and story drifts that make repairs unfeasible, (2) direct economic losses that exceed the limit set by insurance providers, triggering full-value payout and leading to complete replacement, and (3) damage to key structural components that could significantly impede the repair process. Ramirez and Miranda (2012) developed a framework for incorporating the cost of demolition given noncollapse into building loss estimation procedures. The methodology uses residual story drifts as a predictor of building demolition, similar to the approach was adopted by FEMA P58-1 (FEMA 2012).

\section{$L S_{5}$ : Collapse}

$L S_{5}$ is associated with complete or partial collapse, which is generally associated with either excessive lateral deformations (sidesway collapse) or the local or global loss of vertical load carrying capacity. Much research has been performed to develop analytical procedures for simulating collapse. Although there are still improvements to be made, the 
existing methods to characterize extreme ground motions and simulate nonlinear structural response provide a robust methodology for developing collapse fragility curves.

Alternatively, empirical or heuristic fragility curves, which are based on sound evidence or specific building types, can also be used.

\section{Modeling Recovery of Functionality at the Building Level Building Recovery Paths}

Five distinct recovery paths are defined on the basis of the limit states discussed previously. The recovery paths are described by using discrete functioning states and the time spent in each state. The functioning states represent the changing condition of the building with respect to its ability to facilitate its intended operation. The functioning states for modeling the recovery of shelter-in-place housing capacity include the following: (1) the building is unsafe to occupy (NOcc), (2) the building is safe to occupy but unable to facilitate normal operations (OccLoss), and (3) the building is fully functional (OccFull). These three states are specific to the shelter-in-place metric and would need to be redefined for other measures of functionality. The key to defining the functioning states is that (1) they must be explicitly linked to the building-level limit states described previously, and (2) each functioning state must be associated with a quantifiable measure of functionality.

The building-level recovery path is conceptually shown in Fig. 3. It is a step function that describes the time spent in each of the discrete functioning states. The recovery path (and recovery function discussed later) is assessed over a predefined period called the control time, $T_{\text {LC }}$ (Cimellaro et al. 2010b); $T_{\text {NOcC }}, T_{\text {OccLoss }}$, and $T_{\text {OccFull }}$ denote the time spent in the NOcc, OccLoss, and OccFull functioning states, respectively. The functioning states that comprise the recovery path for a given building depend on the limit state of that building immediately after the earthquake. For example, a building that is in limit state $L S_{1}$ will only experience the NOcc and OccFull functioning states. On the other hand, a building that is in limit state $L S_{2}$ or $L S_{3}$ will experience all three functioning states. This is illustrated subsequently in the discussion of building recovery paths. The time spent in each functioning state will also vary depending on the level of damage. For example, a building that is in limit state $L S_{4}$, which must be demolished and rebuilt, will spend a significantly greater amount of time in the NOcc state than a building in limit state $L S_{3}$, which only requires repairs.

The recovery time for an individual building is defined as the period between the occurrence of the earthquake and the restoration of full functionality. The recovery time includes (1) the lead time, which is the time required for building inspection and/or 
evaluation, finance planning, architectural/engineering consultations, a competitive bidding process, and mobilizing for construction (Mitrani-Reiser 2007), (2) the repair time needed to restore occupiability, and (3) the repair time needed to restore functionality. The time needed to restore occupiability is measured as the time to complete repairs related to structural safety and internal access, whereas the time needed to restore functionality includes the additional time needed to repair/replace building systems, nonstructural components, and contents that are essential to the building functionality. Both the lead and repair times for structural and nonstructural components depend on the limit state of the building immediately after the event. For example, a building that is in limit state $L S_{1}$ after an event (damage triggers inspection, but the building is found to be safe to occupy and functional) will likely be green tagged and only be out of service for the time it takes to complete the inspection. On the other hand, a building that is in limit state $L S_{2}$ (building is safe to occupy but not functional) may receive a yellow tag, which would require detailed evaluations by a professional engineer before reoccupancy. A building that is red tagged $\left(L S_{3}, L S_{4}\right.$, and $\left.L S_{5}\right)$ may require demolition or extensive repairs, triggering additional lead time for planning, architectural/engineering consultations, possible competitive bidding, and mobilizing for construction. Mitrani-Reiser (2007) developed a performance-based approach to estimating repair times for both structural and nonstructural damage, which incorporates the lead times for different tagging scenarios and the sequencing of repairs. In this study, Mitrani-Reiser's method is used to compute both repair times needed to restore safety/accessibility and functionality.

The recovery paths for each limit state can be derived from the information provided in Table 1, which shows the relevant activities and time spent in each functioning state. The recovery paths are described as follows:

- Recovery path for $L S_{0}$ : This implies that the functionality of the building is not disrupted and the OccFull state is maintained throughout the period after the earthquake.

- Recovery path for $L S_{1}$ : This path is associated with the occurrence of $L S_{1}$, in which the extent of damage triggers inspection but does not compromise the functionality of the building. It is composed of the NOcc and OccFull states. The time spent in the NOcc state is the time to complete inspections. After the inspections, the building is deemed occupiable and fully functional, immediately entering the OccFull state.

- Recovery path for $L S_{2}$ : For $L S_{2}$, the recovery path includes all three functioning states. Like recovery path 1 , the building initially enters the NOcc state until inspections are complete. Following inspections, the building enters the OccLoss state because, despite being safe to occupy, repairs will be needed to restore functionality. The time spent in the OccLoss state is determined by the repair time for those building systems, nonstructural components, and 
content that are essential to the building function. The completion of these repairs returns the building to the fully functional OccFull state.

- Recovery path for $L S_{3}$ : The recovery path for $L S_{3}$ also includes all three functioning states. Initially, the NOCC state includes the inspection and other lead times, along with the time to complete structural repairs needed to restore occupiability. Because $L S_{3}$ is associated with significant structural and nonstructural damage, the lead time will include planning, design consultations, bidding, and mobilizing for construction. After the completion of structural repairs, the recovery will enter the OccLoss state during which the repairs needed to restore functionality are completed. The completion of these repairs would return the building to the OccFull state.

- Recovery path for $L S_{4}$ : In $L S_{4}$, in which the building is irreparably damaged, the recovery path includes the NOcc and OccFull states, in which the NOcc state includes the time to demolish and replace the damaged building. As the recovery of this building involves new construction, occupancy is not likely to be restored before full completion, which is why this path does not include the OccLoss phase.

- Recovery path for $L S_{5}$ : The recovery path associated with partial or complete collapse is very similar to that of the demolition case, the only difference being that $L S_{5}$ would not require any time to assess whether or not the building could or would be repaired. However, this additional time is likely to be insignificant compared with the time needed to replace the building; hence, the recovery paths associated with $L S_{4}$ and $L S_{5}$ are essentially the same.

Table 1. Recovery Path Activities and Times for Each Functional State

\begin{tabular}{|c|c|c|c|}
\hline \multirow{2}{*}{ Recovery path number } & \multicolumn{3}{|c|}{ Time/acitivies in functional state } \\
\hline & NOCC & Occloss & OccFull \\
\hline 0 & 0 & 0 & $T_{\mathrm{LC}}$ \\
\hline 1 & $T_{\mathrm{INSP}}$ & 0 & $T_{\mathrm{LC}}-T_{\mathrm{INSP}}$ \\
\hline 2 & $T_{\text {INSP }}$ & $T_{\text {Func }}$ & $T_{\mathrm{LC}}-T_{\text {INSP }}-T_{\text {FUnC }}$ \\
\hline 3 & $T_{\mathrm{INSP}}+T_{\mathrm{ASMT}}+T_{\mathrm{MOB}}+T_{\mathrm{OCC}}$ & $T_{\text {Func }}$ & $T_{\mathrm{LC}}-T_{\mathrm{INSP}}-T_{\mathrm{ASMT}}-T_{\mathrm{MOB}}-T_{\mathrm{OCC}}-T_{\mathrm{FUNC}}$ \\
\hline 4 & $T_{\mathrm{ASMT}}+T_{\mathrm{MOB}}+T_{\mathrm{REP}}$ & 0 & $T_{\mathrm{LC}}-T_{\mathrm{ASMT}}-T_{\mathrm{MOB}}-T_{\mathrm{REP}}$ \\
\hline 5 & $T_{\mathrm{MOB}}+T_{\mathrm{REP}}$ & 0 & $T_{\mathrm{LC}}-T_{\mathrm{MOB}}-T_{\mathrm{REP}}$ \\
\hline
\end{tabular}

Note: $T_{\mathrm{ASMT}}=$ time to conduct engineering assessment; $T_{\mathrm{FUNC}}=$ time to restore functionality; $T_{\text {INSP }}=$ time to complete inspections; $T_{\mathrm{MOB}}=$ time to mobilize for construction; $T_{\mathrm{OCC}}=$ time to complete repairs needed to restore occupiability/structural safety; $T_{\text {REP }}=$ time to replace building.

Probabilistic Assessment of Recovery of Functionality at Building Level

Each functioning state can be linked to a quantifiable level of functionality. The functionality will typically be specified according to building owner/stakeholder and community resilience needs. For example, the functionality of a hospital might be 
measured by the number of available patient beds or patient waiting times for procedures offered by particular departments (Cimellaro et al. 2011). The functionality associated with the OccFull state is equal to the preearthquake patient bed capacity and waiting time of the hospital. Obviously, the functionality associated with the NOcc state will be zero regardless of the measure of functionality because a building that is not occupiable will not be functional. The level of functionality assigned to the OccLoss state is less obvious and will vary according to the measure of functionality and the postearthquake operating protocol for the facility. For example, in the case of a hospital facility that is in $L S_{2}$, in which the hospital is occupiable but has lost some of its essential services, the hospital administration may choose to halt operations and close the facility until those services are restored. On the other hand, the emergency needs of the community may compel the administration to provide some reduced level of medical treatment that is possible with limited building services. In such cases, the OccLoss state can be assigned a level of functionality that is some fraction of the preearthquake capacity. Another example is the case of residential buildings in a community, in which, from the perspective of the policymakers, functionality is measured by housing capacity or number of persons housed. Where loss of certain building functions would not preclude short-term shelter-in-place requirements, the shelter-in-place functionality could be determined by assuming that the full preearthquake housing capacity is achieved for both the OccFull and OccLoss states. Alternatively, the expected housing capacity at the OccLoss state may need to account for the likelihood that the building is evacuated by its residents, given the loss of a particular service, i.e.

$$
E[q(t) \mid \text { OccLoss }]=[1-P(\text { Evac } \mid \text { OccLoss })][q(t) \mid \text { OccFull }]
$$

where $E[q(t) \mid$ OccLoss $]$ = expected housing capacity for a residential building in the Occloss functioning state; $P($ Evac $\mid O c c L o s s)=$ probability that the building is evacuated, given that it is safe to occupy but without some of its services; and $[q(t) \mid O c c F u l l]=$ housing capacity associated with the OccFull state or the preearthquake housing capacity. The $P$ (Evac|OccLoss) can be determined on the basis of judgment informed by observations from past earthquakes. By knowing the level of functionality associated with each functioning state, the recovery paths for each limit state can be related to recovery functions, as illustrated in Fig. 4 and calculated as follows: 
(3)

$$
\left[q(t) \mid L S_{i}\right]=\left\{\begin{array}{cl}
{[q(t) \mid N O c c]} & t<\left[T_{\text {NOcc }} \mid L S_{i}\right] \\
{[q(t) \mid \text { OccLoss }]} & {\left[T_{\text {NOcC }} \mid L S_{i}\right] \leq t<\left[T_{\text {NOcc }}+T_{\text {OccLoss }} \mid L S_{i}\right]} \\
{[q(t) \mid \text { OccFull }]} & {\left[T_{\text {NOcC }}+T_{\text {OccLoss }} \mid L S_{i}\right] \leq t<T_{\mathrm{LC}}}
\end{array}\right.
$$

where $\left[q(t) \mid L S_{i}\right]=$ time-dependent building functionality given its immediate postearthquake limit state $L S_{i} ;[q(t) \mid N O c c],[q(t) \mid O c c L o s s]$ and $[q(t) \mid O c c F u l l]=$ level of functionality associated with the NOcc, OccLoss, and OccFull states, respectively; $\left[T_{N O c C} \mid L S_{i}\right]=$ time from the earthquake to the end of the NOcc phase associated with limit state $L S_{i} ;\left[T_{N O C C}+T_{O c C L o s S} \mid L S_{i}\right]=$ time from the earthquake to the end of the OccLoss phase for limit state $L S_{i}$.

The building recovery function is computed accounting for the likelihood of the building being in each of the five limit states for a given ground-shaking intensity. This is illustrated in the event tree shown in Fig. 5, in which each limit state is associated with a unique recovery function, computed from Eq. (3). Fig. 5 also incorporates a sixth event, which corresponds to damage below the threshold level that triggers inspection. The uncertainty in the building limit state and expected recovery is determined by the following:

$$
E[q(t) \mid \mathrm{IM}]=\sum_{i=1}^{n_{l s}}\left[q(t) \mid L S_{i}\right] P\left[L S_{i} \mid \mathrm{IM}\right]
$$

where $E[q(t) \mid \mathrm{IM}]=$ expected recovery function given $\mathrm{IM}$; and $P\left(L S_{i} \mid \mathrm{IM}\right)=$ probability that the building is in the ith limit state for a given IM level.

Incorporating the Effect of Externalities and Socioeconomic Factors on Recovery

Externalities are conditions outside of a building's footprint that can impact its postearthquake recovery. The following are some common externalities related to earthquake events:

- All buildings rely on a range of utility services to carry out their day-to-day functions, and disruption of these services can occur as a result of damage within the building footprint or 
utility system failure unrelated to the building. For example, damage to on-site electrical equipment may lead to electrical power outage in a building, but it is more likely the case that the electrical supply is interrupted because of failure within the distribution network. This type of disruption can lead to loss of functionality at the building level and, depending on the duration of the power outage, possibly to longer repair times. The impact of utility system failures could be mitigated by incorporating redundancy into the building system, i.e., by providing on-site emergency generators, water storage tanks, and others.

- Building access can be compromised as a result of risks from adjacent properties with falling or collapse hazards, requiring an otherwise functional building to be vacated. In the 2011 Christchurch earthquake, a number of buildings in the central business district were rendered unusable because they were adjacent to collapse hazards [Earthquake Engineering Research Institute (EERI) 2011]. Conditions such as these have an obvious impact on immediate postearthquake occupancy and functionality and repair times.

- A number of socioeconomic factors can influence the speed of postearthquake recovery. For example, there can be a shortage of the materials and skilled labor needed to conduct repairs caused by demand surge and population displacement after the earthquake. The adverse economic effect of a large earthquake can also present challenges in obtaining financing for building repairs or replacement.

As shown in Fig. 5, externalities can be conceptualized as affecting the specified limit states and recovery times. In cases in which the building is undamaged, i.e., $L S_{0}$ or $L S_{1}$, loss of functionality may occur as a result of external effects, such as utility disruption or damage to neighboring buildings, rendering an undamaged building inaccessible. In such cases, the recovery paths for these limit states can be modified by including the time to mitigate these external disruptions. Similarly, should the externality lead to disruptions that extend beyond the recovery time required for other limit states (e.g., the repairs required for $L S_{2}$ ), then these recovery times can be adjusted. Thus, although the calculation of the external factors is beyond the scope of this study, once calculated, their effects can readily be incorporated in the proposed methodology.

Related to, but distinct from, how they may affect the functionality of intact buildings, externalities can have a significant effect on the duration times for inspection, assessment/design, mobilization, and repairs. These can be incorporated into the current framework by applying amplification/reduction factors to the various time parameters (e.g., $T_{\text {INSP, }} T_{\text {ASMT }}$, and $T_{\text {MOB }}$ ) that are used to compute the recovery path. For example, Comerio (2006) noted that the scale of regional damage as indicated by the number of collapsed and demolished buildings can be linked to the overall pace of recovery. On the basis of this finding, a performance index can be developed to relate the fraction of collapsed buildings within a particular region and used to account for delays caused by regional socioeconomic effects. Miles and Chang (2003) used performance indices that vary between 0 and 1 to represent several factors that affect recovery at the household, 
business, and community scales. Examples of factors relevant to household recovery include (1) the level of indebtedness, (2) the availability of jobs, (3) lifeline and critical facility restoration, and (4) the availability of shelters. The time parameters used in this study can be adjusted according to an appropriate combination of these performance indices.

\section{Community-Scale Recovery Functions}

The schematic community-level recovery curve illustrated in Fig. 6 can provide useful insights into the trajectory of the restoration of functionality within the region over time. It adopts the parameters and general functional form proposed by Cimellaro et al. (2010b). However, whereas Cimellaro et al. define the recovery curve in a generic sense, in this study the recovery curve is specifically defined to describe the restoration of housing within the community. The function that describes community-level recovery is measured as the sum of the recovery curves for the individual buildings after accounting for the variation and spatial correlation of shaking intensity at each site, the effect of externalities, and other socioeconomic factors. The contribution of individual buildings to the functionality of the region depends on the type of building and measure of functionality. For example, buildings that are used as fire stations would obviously not contribute to the housing capacity of the region. This aggregation of building-level functionality would require quantifying the contribution of each building to the defined measure of community function. The housing recovery function is described by the following:

$$
\left[Q(t) \mid E Q_{j}\right]=\sum_{i=1}^{n_{\mathrm{bldg}}} E\left[q_{i}(t) \mid \mathrm{IM}_{i}, E Q_{j}\right]
$$

where $\left[Q(t) \mid E Q_{j}\right]=$ community recovery for scenario earthquake $j ; E\left[q_{i}(t) \mid \mathrm{IM}_{i}, E Q_{j}\right]=$ expected recovery curve for building $i$ at a given ground motion IM level resulting from scenario earthquake $j$; and $n_{\text {bldg }}=$ number of buildings in the community.

The long-term effects of an earthquake on a community can also be described by the cumulative loss of functionality over the course of the recovery period. For example, the loss of housing capacity over the recovery period measured in "person days" can be computed from a community-level recovery curve that has number of residents housed by the community as the measure of functionality. This cumulative loss in functionality for a 
particular earthquake event is illustrated in Fig. 6 and can be described by the following equation:

$$
\left[L Q_{\mathrm{RE}} \mid E Q_{j}\right]=\int_{T_{E}}^{T_{\mathrm{RE}}}\left(Q_{0}-Q(t)\right) d t
$$

where $\left[L Q_{\mathrm{RE}} \mid E Q_{j}\right]=$ loss of functionality over the recovery period for scenario earthquake $j ; Q_{0}=$ preearthquake level of functionality; $T_{E}=$ time of the earthquake; and $T_{\mathrm{RE}}=$ time at full recovery.

Eq. (6) describes the cumulative loss of functionality for a single-scenario earthquake. Multiple-scenario earthquakes can be considered and used to describe the annual exceedance rate for specified amounts of cumulative loss. This is obtained by computing the cumulative loss for multiple earthquake scenarios each with a different magnitude, location, and annual rate of occurrence. The rate of exceedance, $\lambda$, for specified loss levels is estimated by summing the occurrence rate for all scenarios in which the loss threshold of interest is exceeded

$$
\lambda_{L Q_{\mathrm{RE}} \geq l q}=\sum_{j=1}^{J} w_{j} I\left(L Q_{\mathrm{RE}} \geq l q\right)
$$

where $w_{j}=$ occurrence rate for scenario $j$; and $l q=$ cumulative loss threshold. The indicator function $I\left(L Q_{\mathrm{RE}} \geq l q\right)$ is set to 1 if the argument $L Q_{\mathrm{RE}} \geq l q$ is true and to 0 otherwise.

\section{Case Study}

The proposed methodology is implemented in a case study to model the postearthquake loss and recovery of the housing capacity of a residential community. The hypothetical community consists of three multifamily residential buildings constructed with reinforced concrete frames with masonry infills. The case buildings have 4, 6, and 10 stories with preearthquake occupancies of 65,82 , and 165 residents, respectively. The buildings were designed in accordance with Indian building code IS 1893 [Bureau of Indian Standards (BIS) 2000] as part of a larger study to assess the impact of enhanced seismic performance of 
framed infill buildings with elastic rocking spines on the resilience of a residential community in Noida, India. More details on the development of the building cases can be found in Burton (2014).

Three-dimensional numerical models of the buildings are simulated by nonlinear response history analysis using OpenSees under the 22 pairs of far-field ground motions provided in the FEMA P695 (FEMA 2009) guidelines. The FEMA P695 scaling method is used on the basis of geometric-mean spectral intensity of the ground motion pairs with an adjustment to account for the effect of spectral shape (application of spectral shape factors to collapse fragility). Beams and columns are modeled as elastic with concentrated nonlinear springs that incorporate flexural hinging, and the infill panels are modeled by using inelastic diagonal struts that incorporate strength and stiffness degradation. The demolition limit state is assessed by using the methodology described by Miranda and Ramirez (2012), and the collapse limit state is assessed as presented in Burton and Deierlein (2014). With the shelter-in-place capacity as the recovery metric of interest, it is assumed that a residential building will be fully occupied if it is determined to be safe for occupancy after being inspected, i.e., $P$ (Evac|OccLoss) from Eq. (3) is assumed as 0 . This also implies that a building that is structurally safe to occupy is functional; therefore, an evaluation of $L S_{2}$ is not required for this assessment. Although this assumption is used for this illustrative example, it is not applicable to all communities and residential building types.

Postearthquake structural safety and inspection limit states are assessed by using a new methodology, outlined by Burton (2014), which integrates visual damage simulation, virtual inspection, and an assessment of the residual collapse capacity of damaged buildings.

The following steps are applied to assess the immediate postearthquake reduction and recovery of the shelter-in-place capacity of the hypothetical three-building residential community:

1. The Boore-Atkinson (2008) empirical ground motion prediction equation is used to obtain spectral intensities at the building sites for a magnitude 7 scenario earthquake with epicentral distances of $60 \mathrm{~km}$ for the 4-story building and $63 \mathrm{~km}$ for the 6 - and 10-story buildings. On the basis of the calculated fundamental building periods of $0.7,1.1$, and $1.7 \mathrm{~s}$, the median spectral intensities are $0.24,0.16$, and $0.11 \mathrm{~g}$ for the $4-, 6-$, and 10 -story buildings, respectively. These are roughly one-third of the maximum considered earthquake hazard-level intensities, assumed in the building designs, of $0.60,0.53$, and $0.39 \mathrm{~g}$, respectively.

2. For the magnitude 7 scenario earthquake, 1,000 realizations of spatially correlated spectral intensity residual terms are sampled. The intraevent residual is modeled as a spatially correlated multivariate normal distribution after Jayaram and Baker (2009) by using distances of $3 \mathrm{~km}$ between the 4- and 6-story sites and 4- and 10-story sites and $0.25 \mathrm{~km}$ between the 6and 10-story sites. The total log spectral intensities are computed from the log of the 
predicted intensities and the sampled residuals. The resulting distribution of spectral intensities at the 4-story building site is shown in Fig. 7.

3. For each of the 1,000 spectral intensities associated with each building site, the expected building-level recovery function is computed by using Eqs. (3) and (4) and the probability distribution from the limit state fragilities. The following assumptions are used in calculating the expected recovery function for each simulation $E[q(t) \mid \mathrm{IM}]$ :

- The structural repair time that corresponds to $T_{\text {OCC }}$ is computed from componentlevel damage assessment by using the methodology developed by Mitrani-Reiser (2007). The duration of repairs for each component is treated as a random variable, modeled with a lognormal distribution with mean component repair times as documented in Burton (2014) and an assumed dispersion of 0.4 following FEMA P58-1 (FEMA 2012). Fig. 8(b) plots the resulting mean structural repair time versus ground motion spectral intensity for the 4-story building. The mean repair time is capped at a replacement time of 210 days for the 4-story building and 300 and 435 days for the 6 and 10 -story buildings, respectively.

- The lead times ( $T_{\text {INSP, }}, T_{\mathrm{ASMT}}$, and $T_{\mathrm{MOB}}$ ) are also modeled as random variables, assuming a lognormal distribution with the median values shown in Table 2. A dispersion of 0.75 is assumed, recognizing that there is a greater level of uncertainty associated with these times compared with the repair durations.

4. By using the three building recovery curves, the community-level recovery function for the magnitude 7 scenario is then computed from Eq. (5). The effects of externalities and socioeconomic factors are only implicitly considered, as discussed further in the results.

Table 2. Limit State Fragility Parameters and Median Lead Times Used to Model Recovery

\begin{tabular}{lcccccc}
\hline \multirow{2}{*}{ Limit state } & \multicolumn{3}{c}{ Median SaT1 (g) (dispersion) } & \multicolumn{3}{c}{ Median lead times (days) } \\
\cline { 2 - 7 } & 4-story & 6-story & 9-story & $T_{\text {INSP }}$ & $T_{\text {ASMT }}$ & $T_{\text {MOB }}$ \\
Inspection $\left(L S_{1}\right)$ & $0.14(0.8)$ & $0.12(0.8)$ & $0.08(0.9)$ & 30 & 0 & 0 \\
Unoccupiable $\left(L S_{3}\right)$ & $0.28(1.0)$ & $0.25(1.2)$ & $0.09(1.2)$ & 30 & 60 & 120 \\
Demolition $\left(L S_{4}\right)$ & $0.99(0.6)$ & $0.80(0.8)$ & $0.80(0.7)$ & 30 & 60 & 365 \\
Collapse $\left(L S_{5}\right)$ & $1.13(0.7)$ & $0.94(0.7)$ & $0.83(0.7)$ & 0 & 0 & 365 \\
\hline
\end{tabular}

Fig. 8(a) shows the limit state fragility plot for the 4-story building, which provides the probability of exceedance of each limit state given an observed spectral intensity. The probability of being in a particular damage state, as required for Eq. (4), is calculated as the difference in the probability of exceedance of consecutive limit states. For example, the probability of being in limit state $L S_{4}$ is the difference in the probability of exceedance of limit states $L S_{4}$ and $L S_{5}$. The limit state fragility parameters (median intensity and dispersion) for the three building cases are reported in Table 2. 
The recovery curve for the 4-story building, corresponding to the scenario earthquake defined previously, is shown in Fig. 9 with the solid line. The curve takes on a concave shape with a steep slope in the first 50 days of the recovery. The shape of the building-level recovery curve is related to the probability distribution of the limit states. For a fuller illustration, three variations of the 4-story building recovery curve are generated by scaling the simulated spectral intensities at that site by factors of 2, 3, and 4. As shown in Fig. 9, this scaling increases the initial loss and tends to flatten the recovery curve, as higher ground motion intensities lead to more significant damage and longer recovery times. The immediate postearthquake loss in the expected housing capacity is related to the probability of being in either of the four limit states, i.e., $P\left(L S_{1} \cup L S_{3} \cup L S_{4} \cup L S_{5}\right)$. For the baseline scenario, the probability distribution at the predicted spectral intensity of $0.24 \mathrm{~g}$ (without residuals) is $0.24,0.31$, and 0.45 for $L S_{0}, L S_{1}$, and $L S_{3}$, respectively, and approximately 0 for $L S_{4}$ and $L S_{5}$. The probability of being in limit state 1 or higher is 0.76 and hence the $73 \%$ expected loss in immediate postearthquake housing capacity shown in Fig. 9. The initial slope of the recovery curve is driven by the probability of occurrence of the inspection limit state. This probability decreases with increasing shaking intensity, leading to a flattening in the initial slope. In contrast, the slope of the tail end of the recovery curve is influenced by $L S_{4}$ and $L S_{5}$. As such, it can be observed that as the probability of occurrence of these limit states increase with shaking intensity, the slope of the recovery tail increases. The change in the shape of the recovery curve with the distribution of limit states also applies at the community scale. The results of this type of assessment can be used to calibrate the analytical building-level recovery functions (linear, trigonometric, and exponential), such as proposed by Cimellaro et al. (2010b).

The residential housing (shelter-in-place) recovery curve for the hypothetical three-building community is shown in Fig. 10. It shows that the housing capacity at the community scale is reduced by approximately $56 \%$ immediately after the scenario earthquake. The speed of recovery can be measured by the time to restore the housing capacity to a specified percentage of the preearthquake capacity. From Fig. 10, the time to restore 75 and $95 \%$ of the preearthquake housing capacity of the community is approximately 150 and 660 days, respectively. Such estimates can provide valuable insights into the potential for significant outmigration of residents after an earthquake and the temporary housing needs of the community. Another useful metric that can be obtained from the recovery curve is the cumulative loss of occupancy over the course of the recovery period. By using Eq. (6), this cumulative impact is computed to be $3.7 \times 10^{4}$ person-days for the community-level recovery, assuming a control time of 660 days (time to restore $95 \%$ of preearthquake capacity), measured from the time of the earthquake. To put this in perspective, this loss represents $18 \%$ of the preearthquake cumulative occupancy integrated over the same 
control time. This metric can provide insights into the long-term economic impact associated with the recovery of the housing capacity, such as related to the loss of household income for those displaced residents. The effect of externalities and socioeconomic factors is considered by exploring the effect of the lead time parameters on the recovery trajectory. The dashed recovery curves in Fig. 10 show how the community recovery changes as the assumed median lead time parameters ( $T_{\text {INSP }}, T_{\mathrm{ASMT}}$, and $T_{\mathrm{MOB}}$ ) increase. Fig. 10 shows how the expected recovery curve tends toward a double curvature shape (concave downward in initial stages and convex downward in later stages) as the lead time increases. The cumulative loss increases to 26 and $34 \%$ of the equivalent preearthquake occupancy as the lead time increases by factors of 2 and 4 , respectively. Together, the building and community recovery curves can provide insights on how the community resilience can be affected by a combination of (1) changes in building design and construction, which affects both the immediate impact and recovery trajectory, and (2) measures to accelerate recovery by reducing lead and repair times.

\section{Conclusions}

A comprehensive assessment of seismic resilience requires an interdisciplinary approach in which information related to several fields (e.g., engineering, economics, and social sciences) is integrated to understand both the immediate and cumulative impacts of earthquakes on a community. This paper contributes to the body of work on resilience by extending existing performance-based engineering frameworks to incorporate a probabilistic assessment of building performance and recovery curves. The limit states have been adapted from the building performance categories defined in SPUR's resilient city initiative (Poland et al. 2009) and are explicitly linked to recovery-related activities. Models of recovery at the building scale account for uncertainties in the occurrence of these limit states. Guidelines are provided for incorporating the effect of conditions outside a building's footprint and other socioeconomic factors on recovery. These factors can influence both the immediate postearthquake functionality and the time to full recovery. The framework has been developed with a specific focus on modeling the recovery of the shelter-in-place capacity of residential communities. This is demonstrated in a case study on a hypothetical three-building residential community for a single-earthquake scenario. The results of the case study are used to establish a link between the distribution of the building limit states and the shape of the recovery curve. This relationship can be used to calibrate previously proposed analytical recovery functions. The overall pace of recovery is measured by using several metrics that are shown to provide useful information that could inform the temporary housing needs and the cumulative effects of an earthquake on a community. Future work will focus on extending the framework to include more 
comprehensive measures of resilience, including such things as complex agentenvironment relationships and interactions that are not currently addressed.

\section{Acknowledgments}

The authors would like to thank the anonymous reviewers of this paper for their feedback. This research was partially supported by the John Blume Earthquake Engineering Center, the Engineering Diversity Fellowship, and the Diversifying Academia Recruiting Excellence (DARE) Fellowship at Stanford University. The computational models run for this study used the Extreme Science and Engineering Discovery Environment (XSEDE), which is supported by National Science Foundation Grant No. OCl-1053575 (Allocation: TG-BCS130008).

\section{Figures}

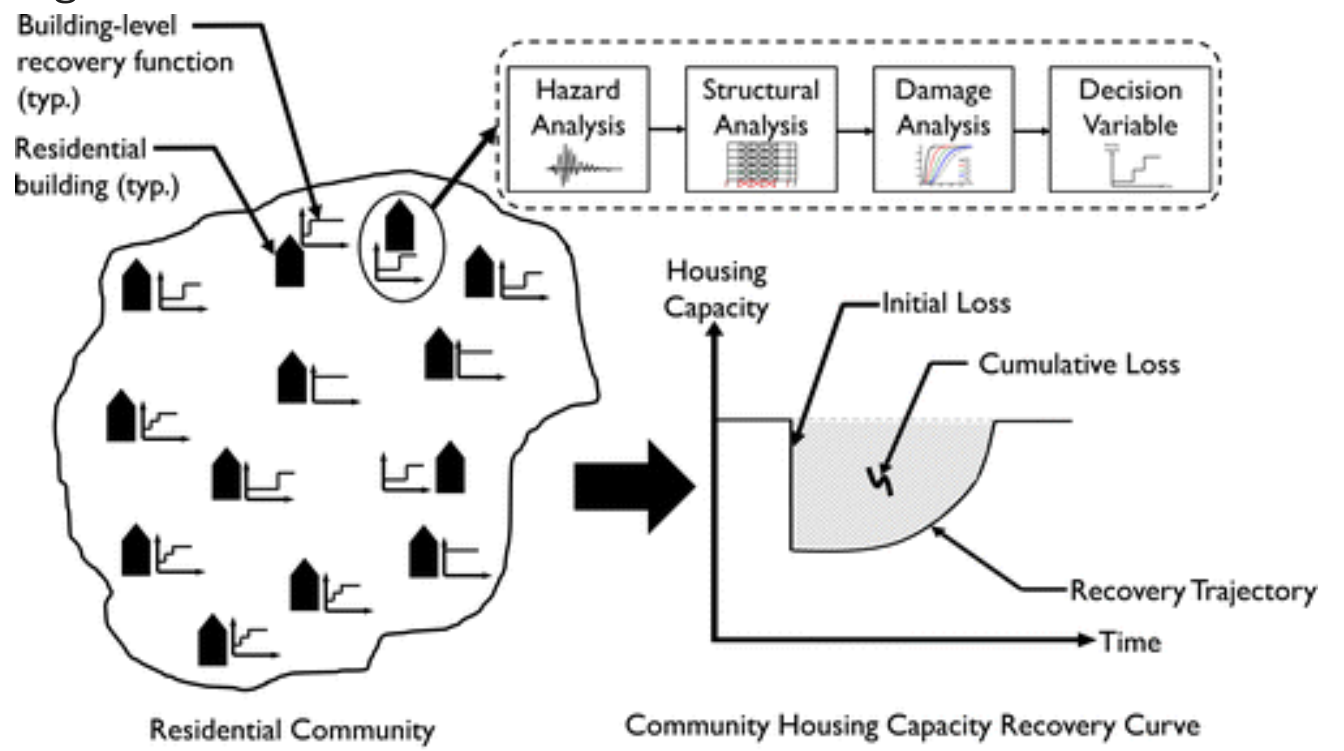

Fig. 1. Conceptual representation of proposed framework

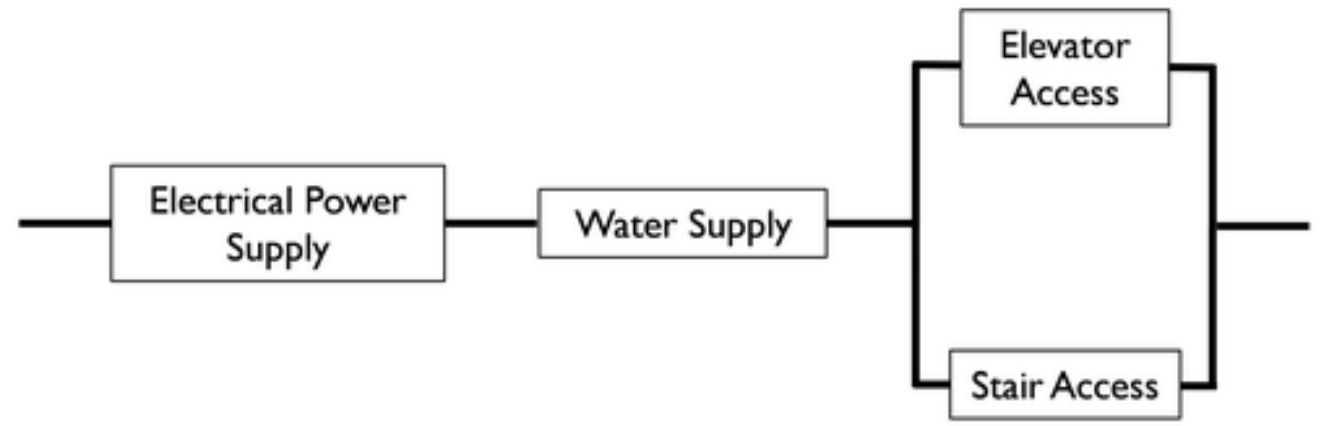

Fig. 2. Functional block diagram for residential building 


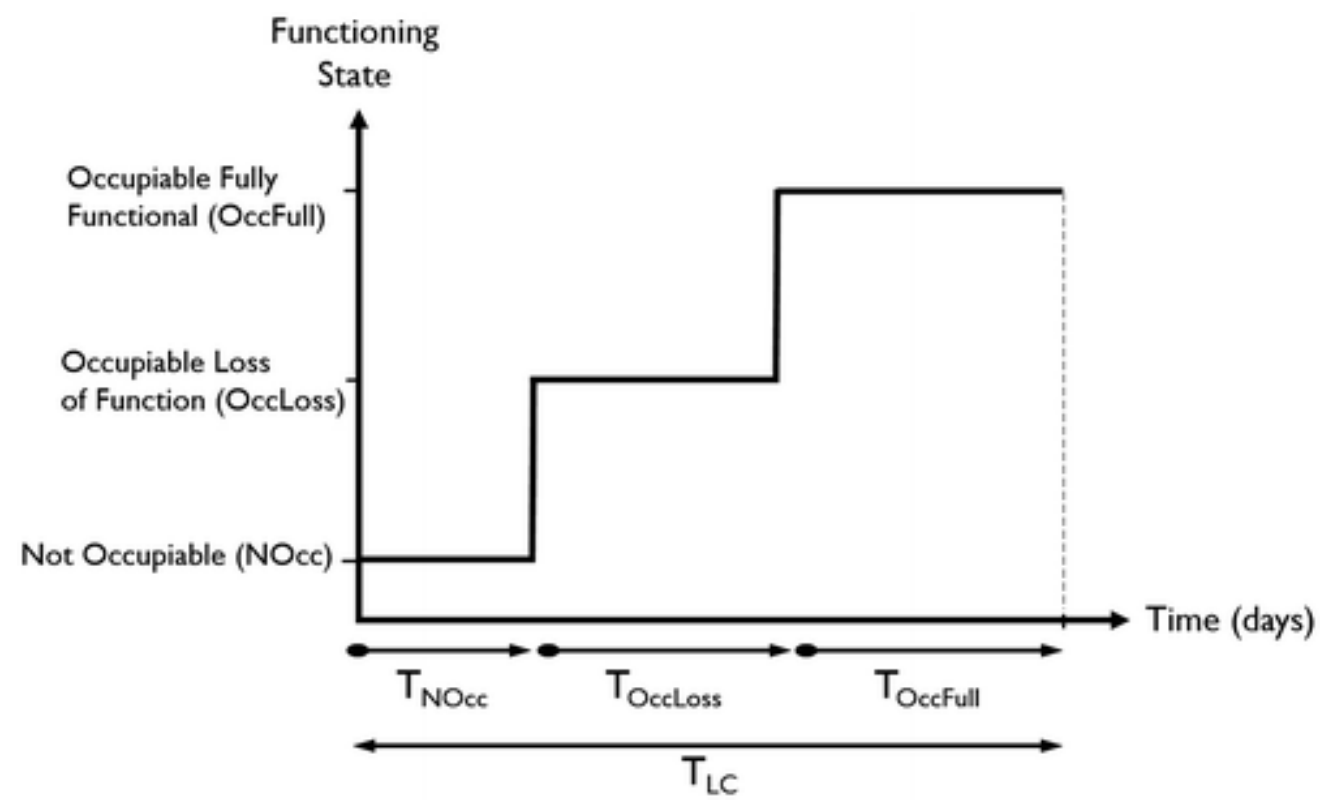

Fig. 3. Conceptual illustration of recovery path for an individual building
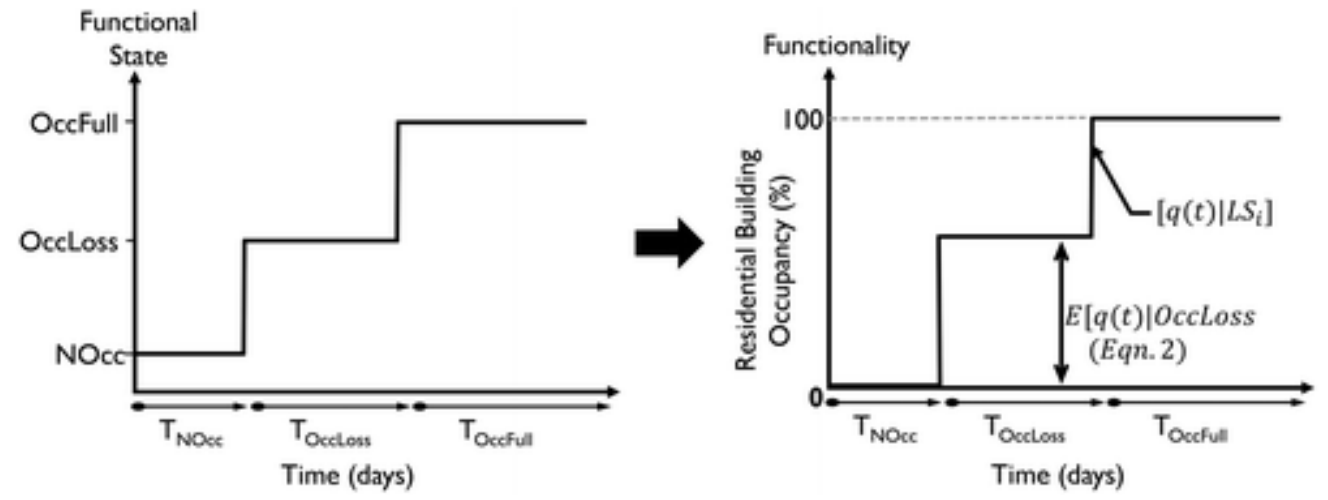

Fig. 4. Conversion from recovery path to recovery function for residential building occupancy



$$
E[q(t) \mid I M]
$$

Fig. 5. Limit state event tree to assess building-level recovery 


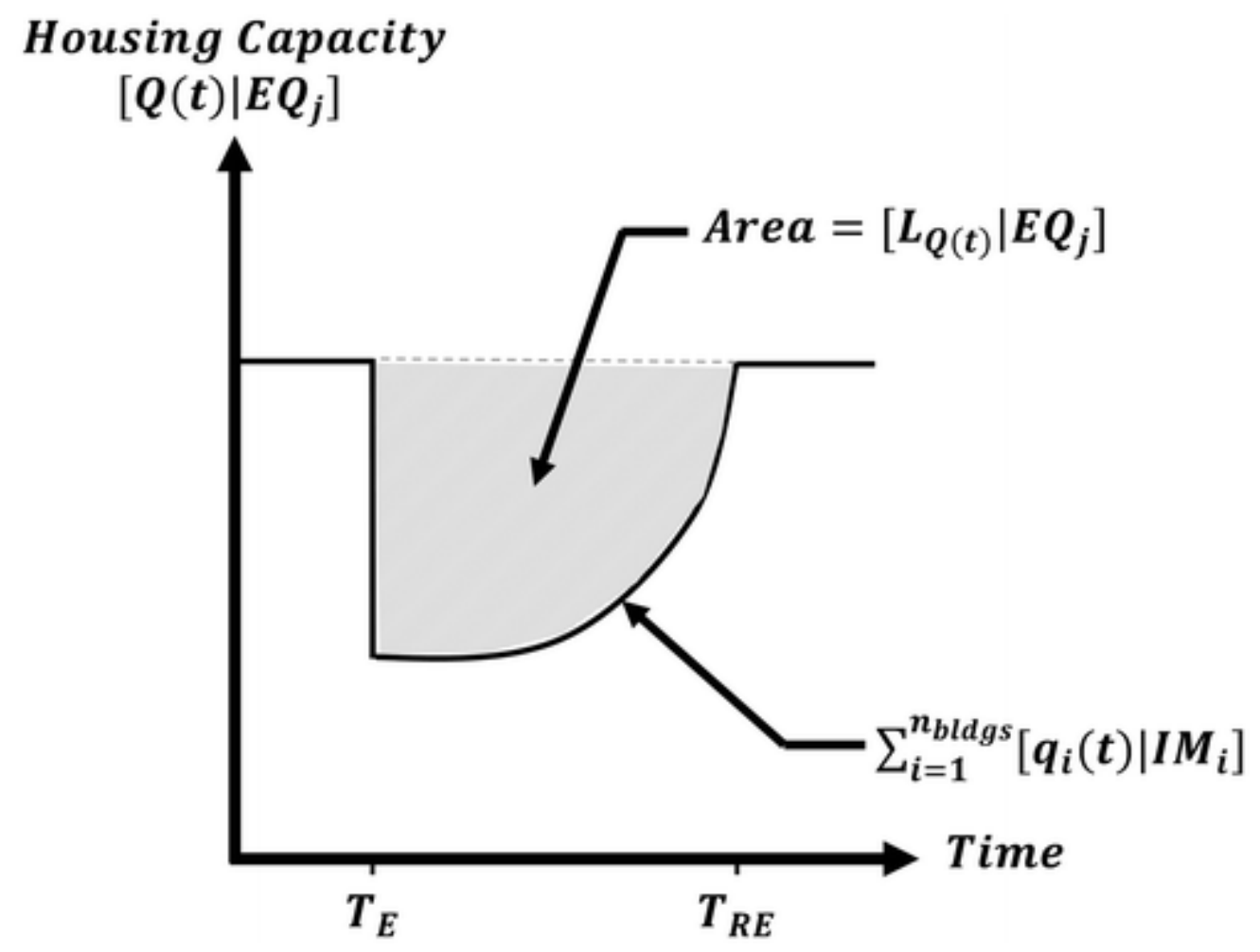

Fig. 6. Community-scale recovery curve

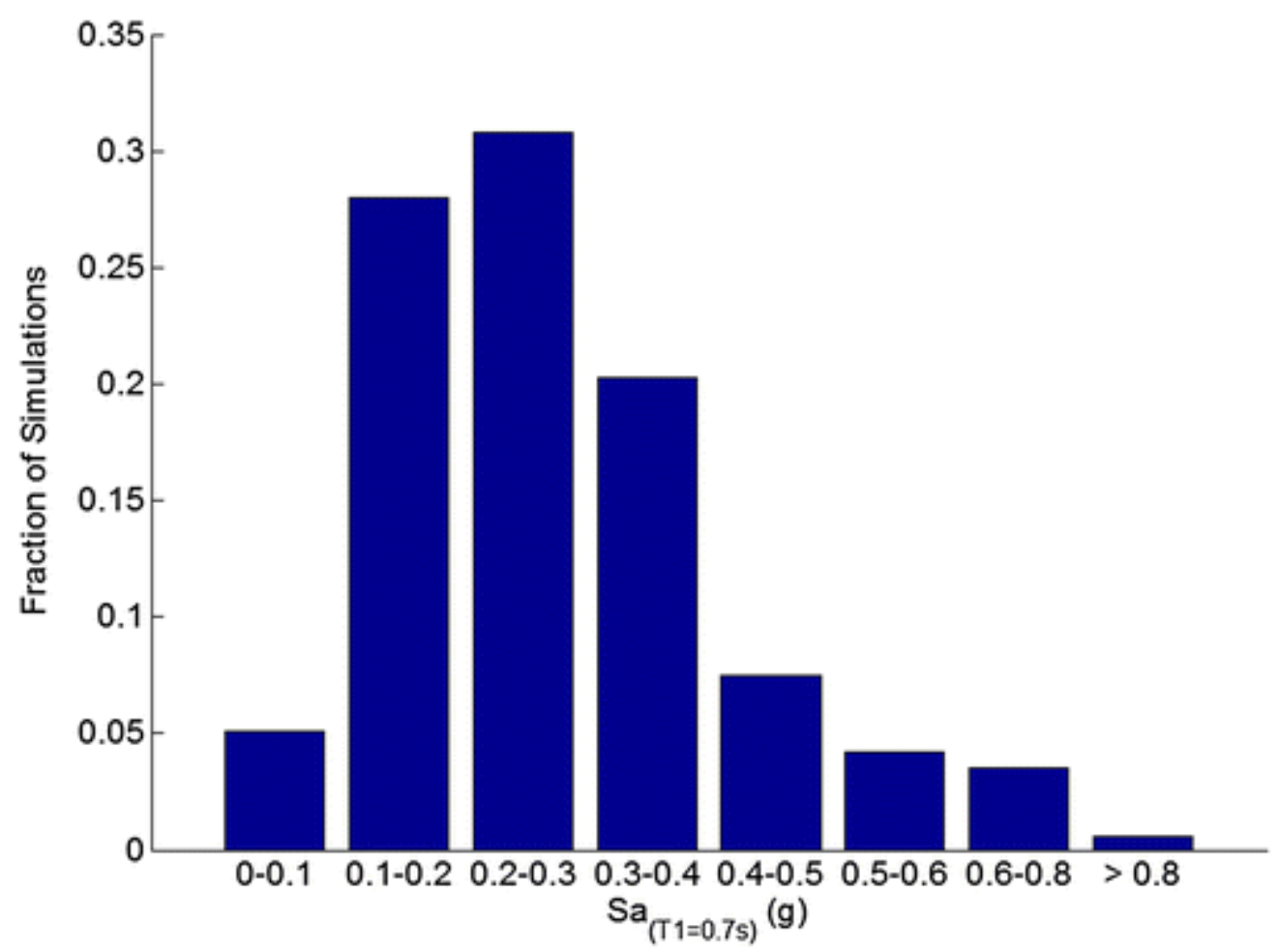

Fig. 7. Distribution of spectral intensities used to assess damage and recovery for 4-story building 

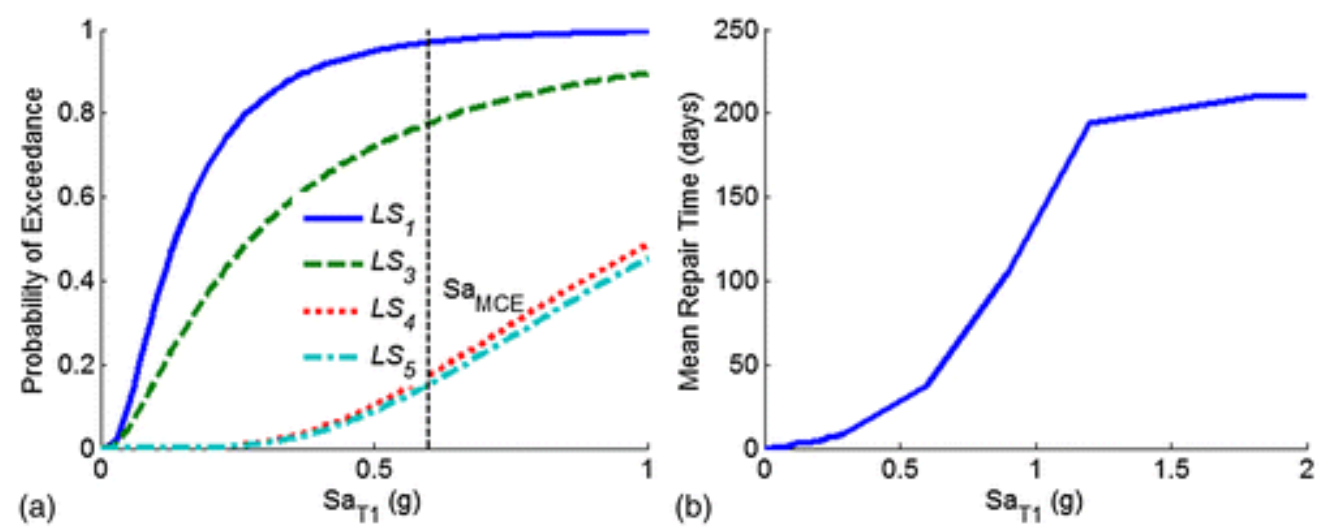

Fig. 8. Characteristic performance data for 4-story building: (a) limit state fragility curves; (b) mean repair time to restore occupancy $\left(T_{\text {OCC }}\right)$ versus ground motion spectral intensity

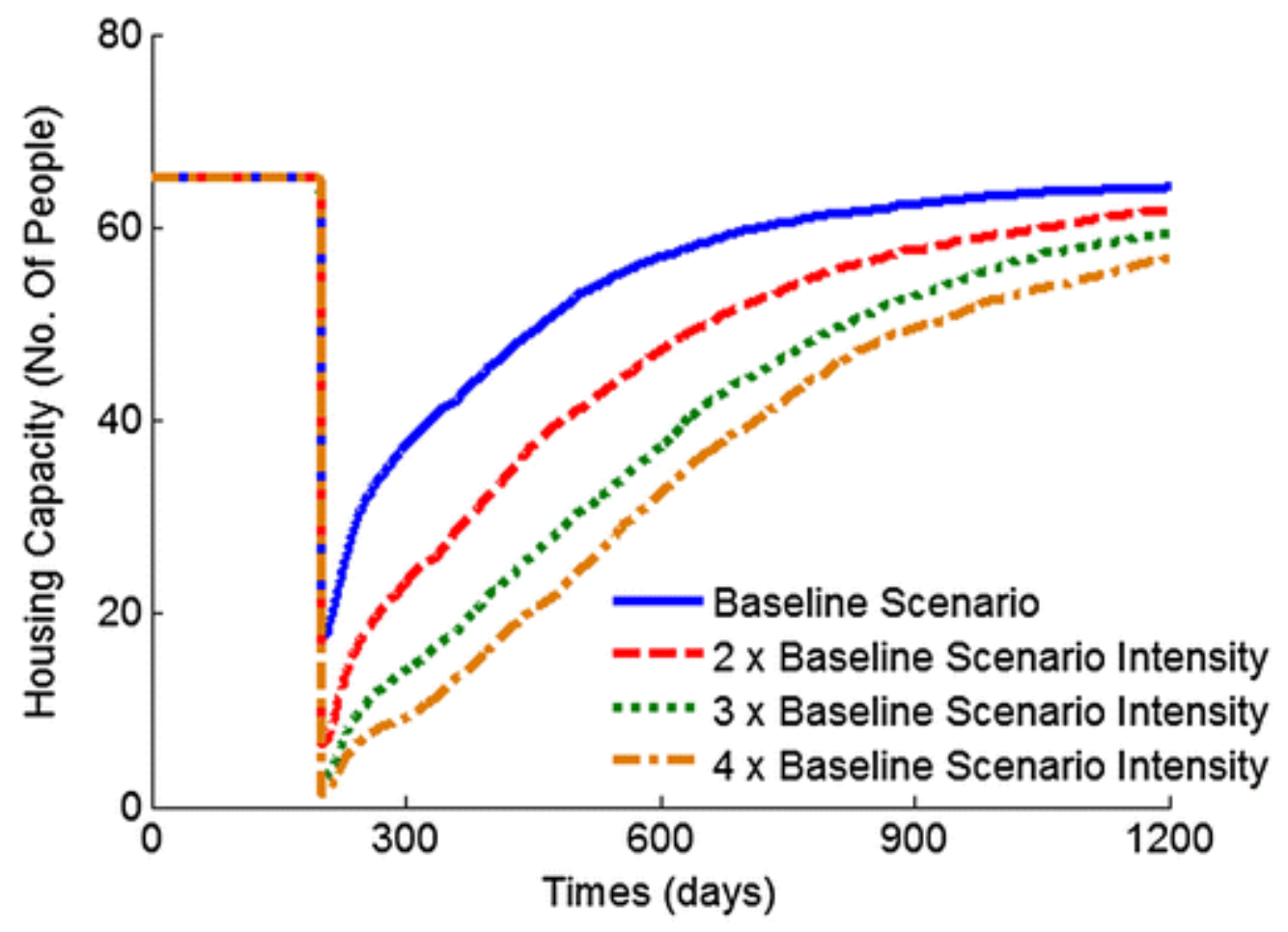

Fig. 9. Recovery curve for 4-story building examining effect of limit state probability distribution 


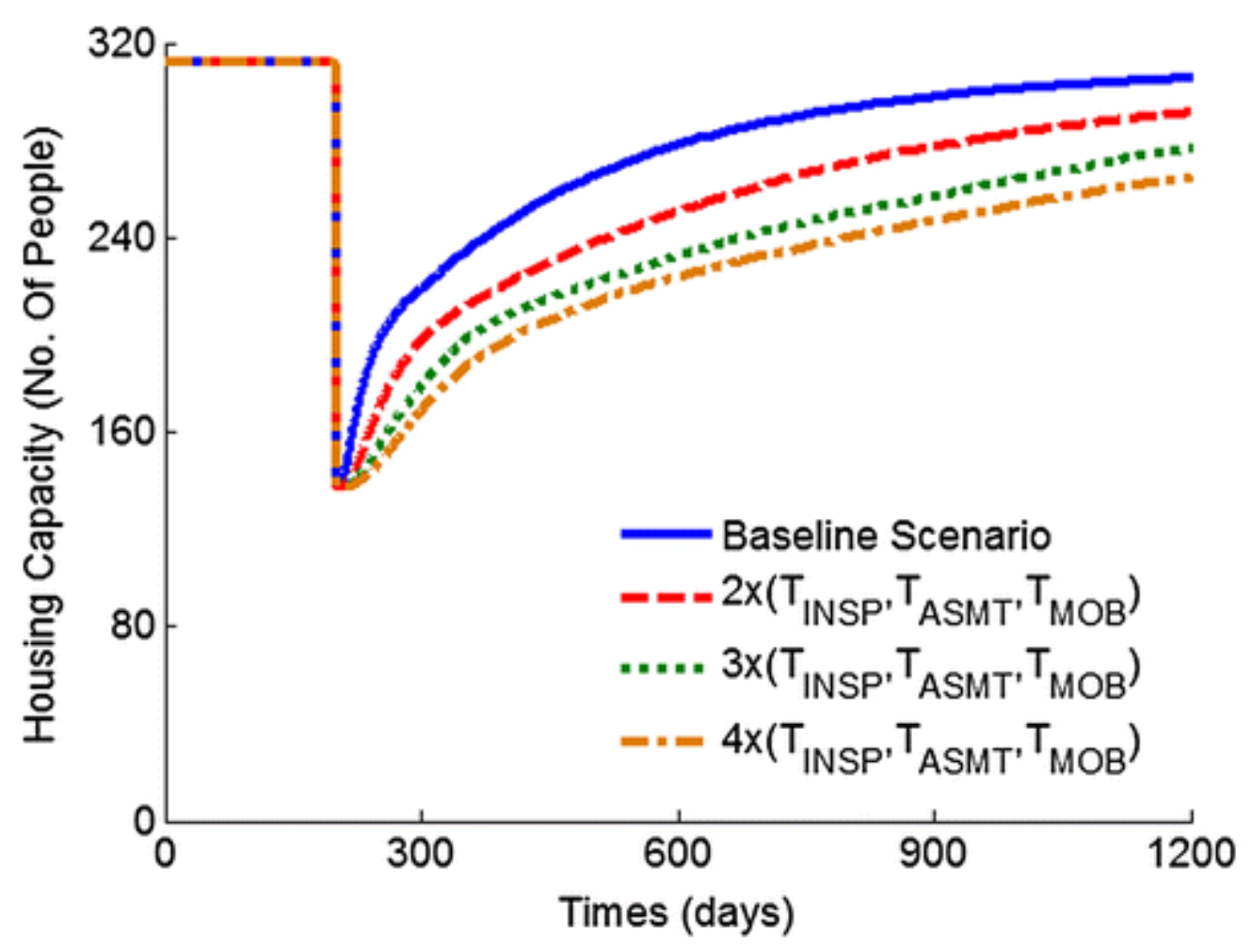

Fig. 10. Community-level recovery function

\section{References}

BIS (Bureau of Indian Standards). (2000). Criteria for earthquake resistant design of structures, IS 1893, New Delhi, India.

Boore, D. M., and Atkinson, G. M. (2008). "Ground-motion prediction equations for the average horizontal component of PGA, PGV, and 5\%-damped PSA at spectral periods between $0.01 \mathrm{~s}$ and 10.0 s." Earthquake Spectra, 24(1), 99-138.

Bruneau, M., et al. (2003). "A framework to quantitatively assess and enhance the seismic resilience of communities." Earthquake Spectra, 19(4)), 733-752.

Burton, H. V. (2014). "A rocking spine for enhanced seismic performance of infill frames." Ph.D. dissertation Stanford Univ., Stanford, CA.

Burton, H. V., and Deierlein, G. G. (2014). "Simulation of seismic collapse in nonductile reinforced concrete frame buildings with masonry infills." J. Struct. Eng., 10.1061/(ASCE)ST.1943-541X.0000921, A4014016.

Cimellaro, G., Christovasilis, I., Reinhorn, A., De Stefano, A., and Kirova, T., (2010a). "L'Aquila earthquake of April 6, 2009, in Italy: Rebuilding a resilient city to withstand multiple hazards." MCEER-10-0010, Multidisciplinary Center for Earthquake Engineering Research, Buffalo, NY.

Cimellaro, G., Reinhorn, A., and Bruneau, M., (2010b). “Framework for analytical quantification of disaster resilience." Eng. Struct., $\underline{32}(\underline{11}), 3639-3649$.

Cimellaro, G., Reinhorn, A., and Bruneau, M. (2011). “Performance-based metamodel for healthcare facilities." Earthquake Eng. Struct. Dyn., $\underline{40}(\underline{11}), 1197-1217$. 
Comerio, M. (2006). "Estimating downtime in loss modeling." Earthquake Spectra, 22 (22), 349-365.

Cornell, A., and Krawinkler, H. (2000). "Progress and challenges in seismic performance assessment." PEER Newsletter, Pacific Earthquake Engineering Research Center, Univ. of California, Berkeley, CA.

Cutter, S. L., Burton, C. G., and Emrich, C. T. (2010). "Disaster resilience indicators for benchmarking baseline conditions." J. Homeland Secur. Emerg. Manage., 그모).

EERI (Earthquake Engineering Research Institute). (2011). "The M6.3 Christchurch, New Zealand, earthquake of February 22, 2011." Special Earthquake Rep. Oakland, CA.

FEMA. (1999). "HAZUS earthquake loss estimation methodology." Technical Manuals I, II, and III, Prepared by the National Institute of Building Sciences for FEMA, Washington, DC.

FEMA. (2009). "Quantification of building seismic performance factors." FEMA P695, Applied Technology Council, Redwood City, CA.

FEMA. (2012). "Seismic performance assessment of buildings." FEMA P58-1, Applied Technology Council, Redwood City, CA.

Jayaram, N., and Baker, J. W. (2009). "Correlation model for spatially distributed ground-motion intensities." Earthquake Eng. Struct. Dyn., 38, 1687-1708.

Krawinkler, H., and Deierlein, G. (2013). "Challenges towards achieving earthquake resilience through performance based earthquake engineering." Chapter 1, Performance-based seismic engineering: Vision for an earthquake resilient society, M.Fischinger, ed., Springer, New York.

Krawinkler, H., Miranda, E., Bozorgnia, Y., and Bertero, V. V. (2004). "Performance-based earthquake engineering." Chapter 9, Earthquake engineering: From engineering seismology to performance-based engineering, CRC, FL.

Mieler, M., Stojadinovic, B., Budnitz, R., Comerio, M., and Mahin, S. (2014). "A framework for linking communityresilience goals to specific performance targets for the built environment." Earthquake Spectra, in press.

Miles, S. B. (2014). "Modeling and visualizing infrastructure-centric community disaster resilience." Proc., 10th U.S. National Conf. on Earthquake Engineering, Anchorage, AK.

Miles, S. B., and Chang, S. E. (2003). “Urban disaster recovery: A framework and simulation model.” MCEER-03-0005, Multidisciplinary Center for Earthquake Engineering Research, Buffalo, NY.

Miles, S. B., and Chang, S. E. (2006). "Modeling community recovery from earthquakes." Earthquake Spectra, 222(2)), 439-458.

Miles, S. B., and Chang, S. E. (2007). "A simulation model of urban disaster recovery and resilience: Implementation for the 1994 Northridge earthquake." MCEER-07-0014, Multidisciplinary Center for Earthquake Engineering Research, Buffalo, NY.

Miles, S. B., and Chang, S. E. (2011). "ResilUS: A community based disaster resilience model." Cartogr. Geogr. Inf. Sci., $\underline{38(1)}$, 36-51.

Mitrani-Reiser, J. (2007). "An ounce of prevention: Probabilistic loss estimation for performance-based earthquake engineering," Ph.D. dissertation, California Institute of Technology, Pasadena, CA.

Moehle, J., and Deierlein, G. G. (2004). "A framework methodology for performance-based earthquake engineering." Proc., 13th World Conf. on Earthquake Engineering, Vancouver, BC, Canada, 679.

OpenSees [Computer software]. Berkeley, CA, Univ. of California, Berkeley, Pacific Earthquake Engineering Research Center. 
Poland, C. (2009). "The resilient city: Defining what San Francisco needs from its seismic mitigation polices." 〈 http://www.spur.org/initiative/resilient-city) (Feb. 1, 2009).

Ramirez, C. M., and Miranda, E. (2012). "Significance of residual drifts in building earthquake loss estimation." Earthquake Eng. Struct. Dyn., 41(11), 1477-1493.

Silva, V., Crowley, H., Pagani, M., Monelli, D., and Pinho, R. (2012). "Development and application of OpenQuake, an open source software for seismic risk assessment." Proc., 15th World Conf. on Earthquake Engineering, Lisbon, Portugal, 4917.

Twigg, J. (2009). Characteristics of a disaster-resilient community: A guidance note, 2nd Ed., Disaster Risk Reduction Interagency Coordination Group, London. 